\title{
Effect of quartz and alumina dust on generation of superoxide radicals and hydrogen peroxide by alveolar macrophages, granulocytes, and monocytes
}

\author{
V A Gusev, Ye V Danilovskaja, O Ye Vatolkina, O S Lomonosova, B T Velichkovsky
}

\begin{abstract}
Phagocytosis of quartz particles by rabbit alveolar macrophages and monocytes and human granulocytes and monocytes was accompanied by stimulation of substrate free reduction of nitroblue tetrazolium to formazan. This reflects activation of an oxygen dependent bactericidal system of phagocytes and total (exogenic and endogenic) generation of active oxygen species. Low fibrogenic and cytotoxic alumina dust tended to increase formazan production by comparison with quartz dust. During phagocytosis of quartz dust by alveolar macrophages and monocytes there was no exogenic generation of superoxide radicals and hydrogen peroxide by these cells. By contrast, incubation of human granulocytes with quartz dust caused a significant increase in exogenic generation of superoxide radicals and hydrogen peroxide. Under such conditions, low fibrogenic alumina dust had no effect on hydrogen peroxide generation and substantially decreased the level of superoxide radical generation by human granulocytes. During incubation of rabbit granulocytes with quartz dust, an increase in the level of superoxide radical generation was also detected. It is considered that the differences between alveolar macrophages and granulocytes in their response to quartz dust are important from a physiological point of view. Alveolar macrophages are permanently present in pulmonary alveolae in large quantities; therefore their uncontrolled generation of superoxide radicals and hydrogen peroxide might immediately cause damage to pulmonary parenchyma. At the same time, destruction products from alveo-
\end{abstract}

Laboratory of pathogenesis and experimental therapy of pneumoconiosis, Russian State University of Medicine, Moscow

V A Gusev, Ye V Danilovskaja, O Ye Vatolkina, O S Lomonosova, B T Velichkovsky lar macrophages that died during phagocytosis of quartz particles contain a factor attracting granulocytes. Presence of a significant number of granulocytes in bronchopulmonary lavage fluid in cases of silicosis indicates development of a pathological process. This agrees well with the data obtained on exogenic generation of superoxide radicals and hydrogen peroxide by granulocytes, and on stimulation of this process due to phagocytosis of quartz dust.

(British fournal of Industrial Medicine 1993;50:732-735)

Phagocytosis of quartz particles rapidly causes death of alveolar macrophages, which is considered to be an essential step in the pathogenesis of silicosis. ${ }^{1}$ Progress of the pathological process in lungs in cases of pneumoconiosis is also accompanied by a prominent increase in number of granulocytes in bronchopulmonary lavage fluid from patients and laboratory animals. ${ }^{23}$

Our present study was undertaken to examine the effects of quartz dust and low fibrogenic alumina dust on generation of various active oxygen species by rabbit and human alveolar macrophages, granulocytes and monocytes. The aim was to ascertain the biochemical mechanisms involved in the cells' participation in the pathological process of silicosis.

Materials and methods

Forty male chinchilla rabbits and blood from 45 donors were used for the experiments. Alveolar macrophages were obtained from a rabbit lung by endobronchial washing. ${ }^{4}$ The cells were washed five times with $40 \mathrm{ml}$ of Hanks' solution. Mononuclear cells were obtained from rabbit blood by the method described previously. ${ }^{5}$ Granulocytes were obtained from rabbit blood by methods modified by us as described in previous studies ${ }^{67}$ Blood $(40 \mathrm{ml})$ taken from a rabbit ear artery was mixed with heparin. The blood was diluted by half with $0.9 \%$ sodium chloride solution and mixed with 
$10 \%$ gelatine solution in the ratio $20: 1$. After sedimentation, the supernatant was placed on $5 \mathrm{ml}$ of Percoll (Pharmacia, Sweden), with a density of 1.0815 , and centrifuged at $450 \mathrm{~g}$ for 20 minutes. After centrifugation, the supernatant and Percoll were removed and the precipitate of cells was treated at $37^{\circ} \mathrm{C}$ with $0.83 \%$ ammonium chloride solution, $\mathrm{pH} 7 \cdot 2$ to lyse the erythrocytes. Viability of the released granulocytes was about $95 \%$. Granulocytes and the mononuclear cell fraction were obtained from human blood by the method described elsewhere. ${ }^{8}$ Purity of all cell fractions was established by morphological examination of smears of cell suspensions in plasma after staining (May Grunwald Giemsa). Investigation of active oxygen total generation by cells was carried out by the method of substrate free reduction of nitroblue tetrazolium to formazan. ${ }^{9}$ Cells $\left(3 \times 10^{6}\right)$ were incubated for 15 minutes at $37^{\circ} \mathrm{C}$ in $1 \mathrm{ml}$ of KrebsRinger solution containing $0.5 \mathrm{mM} \mathrm{CaCl} 2,10 \mathrm{mM}$ glucose, and $0.49 \mathrm{mM}$ nitroblue tetrazolium. The reaction was terminated by adding $10 \mathrm{ml}$ of $0.5 \mathrm{~N}$ $\mathrm{HCl}$. The formazan produced was extracted from the precipitate into $4 \mathrm{ml}$ of pyridine by heat for 15 minutes in a boiling water bath. The optical density of the supernatant was measured at $515 \mathrm{~nm}$. The intensity of generation by cells of superoxide radicals was determined by the amount of cytochrome $\mathrm{C}$ reduction inhibited by superoxide dismutase. ${ }^{10}$ The incubation medium was Hanks' solution containing $50 \mu \mathrm{M}$ cytochrome $\mathrm{C}$ or, in the case of human and rabbit granulocytes, bull blood albumin at a concentration of $1 \mathrm{mg} / \mathrm{ml}$. The granulocytes $\left(1.5 \times 10^{6}\right.$ cells $)$ were incubated in $1.5 \mathrm{ml}$ of the medium for 15 minutes at $37^{\circ} \mathrm{C}$, and alveolar macrophages and monocytes for 95 minutes. The reaction was terminated in an ice bath; after centrifugation, optical density was measured at $550 \mathrm{~nm}$ with and without $50 \mu \mathrm{g}$ of superoxide dismutase. Generation of hydrogen peroxide by cells was determined by the method based on phenol red oxidation in the presence of peroxidase. ${ }^{11}$ The incubation medium was Hanks' solution containing $0.28 \mathrm{mM}$ phenol red, horse radish peroxidase at a concentration of $50 \mu \mathrm{g} / \mathrm{ml}$, and $1 \mathrm{mM}$ sodium azide. The cells $\left(3 \times 10^{6}\right)$ were incubated in $3.5 \mathrm{ml}$ medium at $37^{\circ} \mathrm{C}$ for 15 minutes.

\section{Results}

Incubation of rabbit alveolar macrophages and monocytes, as well as of human monocytes and granulocytes with different amounts of quartz dust caused a significant increase in total generation of active oxygen (fig 1). By contrast with silica dust, the less fibrogenic and cytotoxic alumina dust at the same concentrations as those of quartz dust

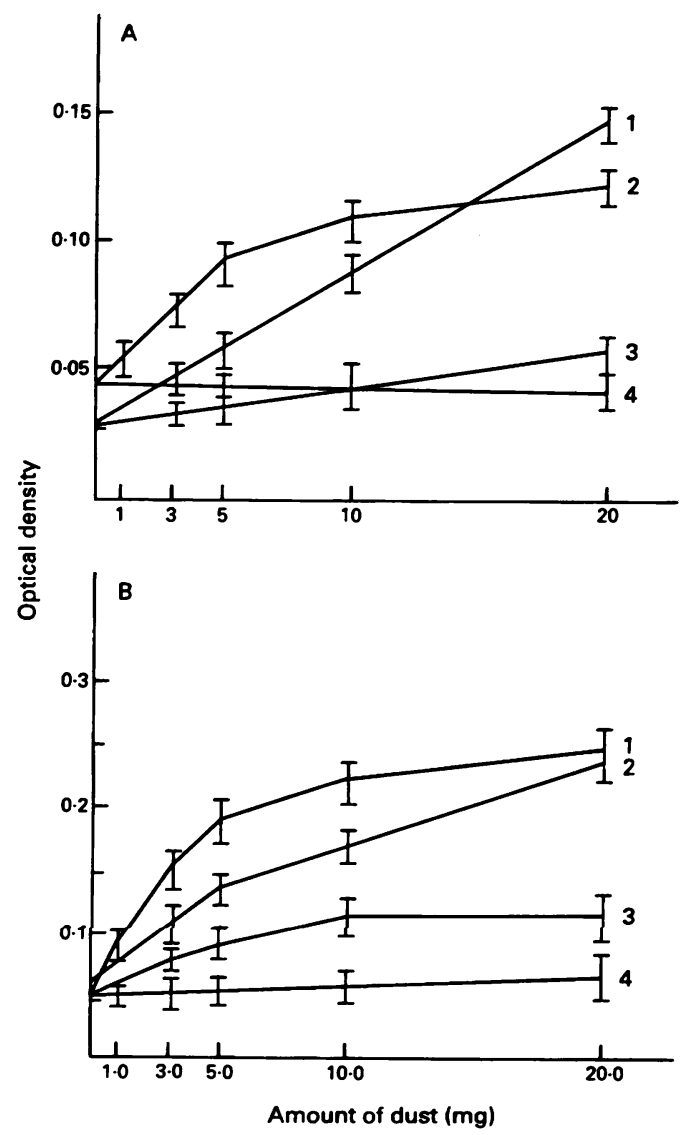

Figure 1 Effect of quartz dust $(1,2)$ and alumina dust $(3,4)$ on reduction of nitroblue tetrazolium by rabbit alveolar macrophages and monocytes $(A)$ and human granulocytes and monocytes $(B)$. For $A, 1,3$ rabbit $A M ; 2,4$ rabbit monocytes; for B, 1,3 human granulocytes; 2,4 human monocytes. Optical density in optical units.

caused much less increase in active oxygen production. There was a considerably higher level of granulocyte response in comparison with other cells. Superoxide dismutase added to the incubation medium had no effect on reduction of nitroblue tetrazolium by alveolar macrophages and monocytes, but inhibited this process by $50 \%$ on average in the case of granulocytes. We did not find exogenic generation of superoxide radicals and hydrogen peroxide by rabbit and human alveolar macrophages and monocytes during phagocytosis of quartz dust. On the other hand, incubation of human granulocytes with quartz dust caused a significant increase in exogenic generation of superoxide radicals, and especially hydrogen peroxide in 


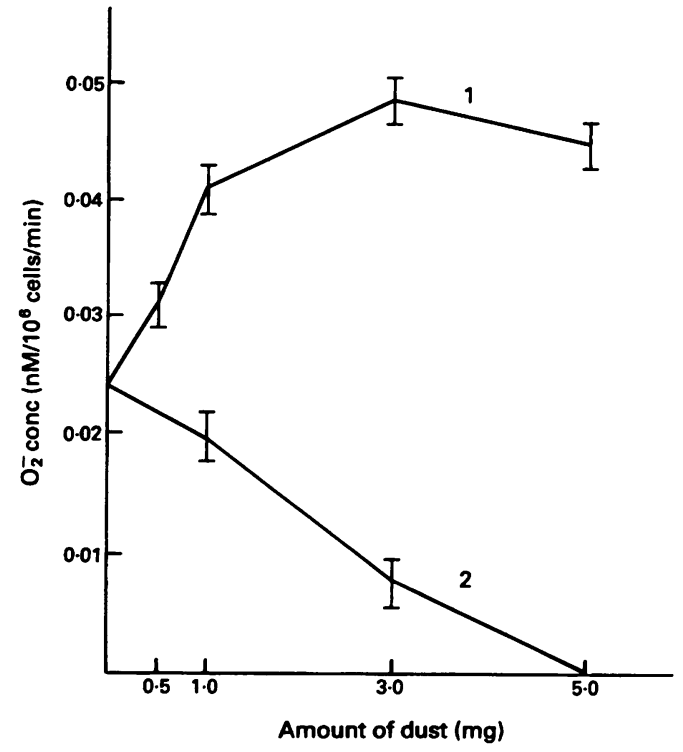

Figure 2 Effect of quartz and alumina dust on generation of superoxide radicals by human granulocytes. 1 Silica dust; 2 alumina dust.

comparison with intact cells (figs 2 and 3). Low fibrogenic alumina dust had no influence on the generation of hydrogen peroxide by human granulocytes and caused a pronounced decrease in the intensity of superoxide radical generation by these cells. Incubation of rabbit granulocytes with quartz dust also caused a considerable increase in exogenic generation of superoxide radicals (fig 4); however, the stimulating effect of quartz dust, by contrast with human granulocytes, was not seen for each rabbit, but only in $60 \%$ of the experiments performed.

\section{Discussion}

The method of substrate free reduction of nitroblue tetrazolium to formazan by phagocytes makes it possible to assess the generation of active oxygen species both inside and outside phagosomes. ${ }^{12}$ The inability of alveolar macrophages and monocytes to generate superoxide radicals and hydrogen peroxide exogenically when stimulated by quartz dust, along with enhanced generation of active oxygen species as a result of interaction with quartz dust, indicate intracellular development of the generation process in the cells. Such a conclusion is confirmed by data showing the absence of any effects of superoxide dismutase added to the incubation medium on nitroblue tetrazolium reduction by alveolar macrophages and monocytes. The difference found between alveolar macrophages and granulocytes in their response to quartz dust is important from a

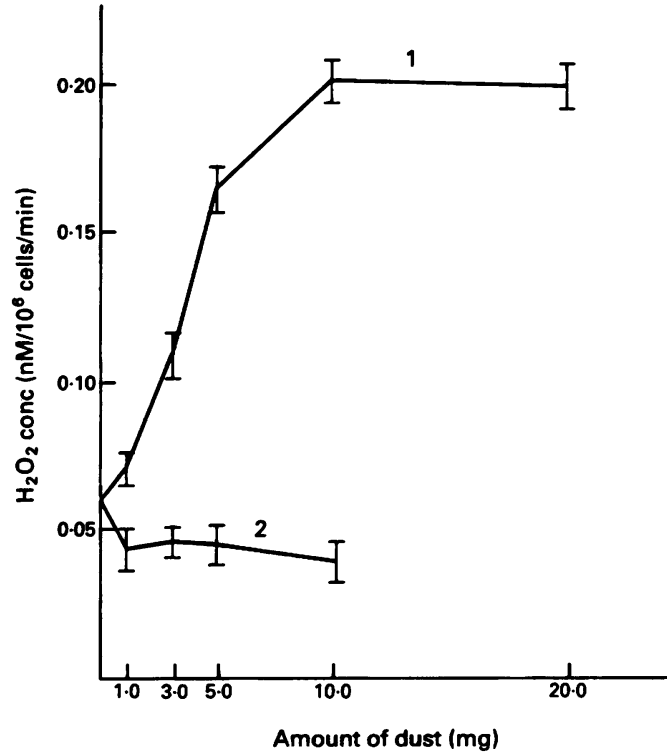

Figure 3 Effect of quartz and alumina dust on generation of hydrogen peroxide by human granulocytes. 1 Silica dust; 2 alumina dust.

physiological point of view. Active oxygen species released by phagocytes possess not only bactericidal properties but exert a powerful damaging action on phagocytes and surrounding tissues. ${ }^{1314}$ Alveolar

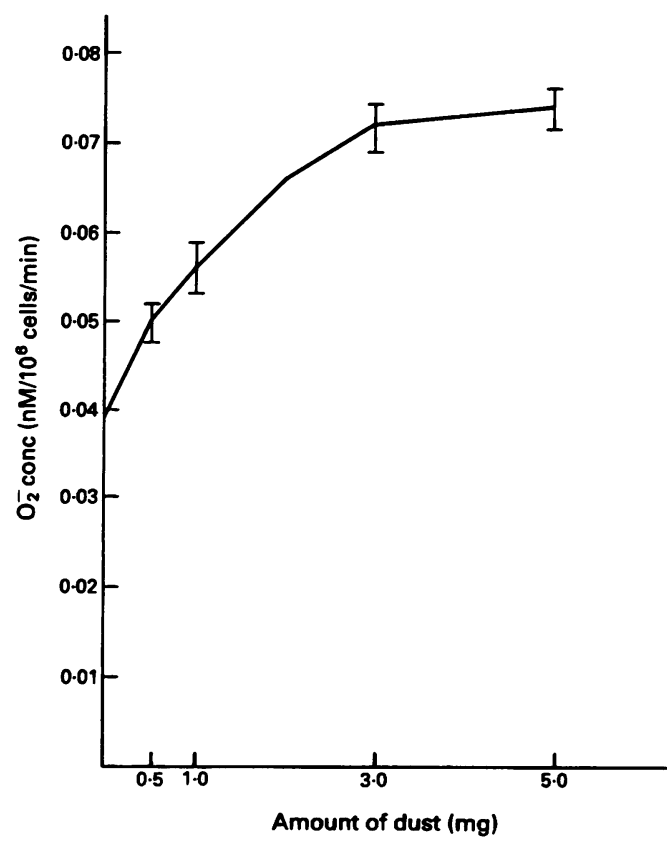

Figure 4 Effect of quartz dust on generation of superoxide radicals by rabbit granulocytes. 
macrophages are permanently present in pulmonary alveolae in large quantities. When quartz dust gets into the lungs, uncontrolled exogenic generation of superoxide radicals and hydrogen peroxide by macrophages might immediately cause damage to pulmonary parenchyma. At the same time, products of destruction of alveolar macrophages after phagocytosis of quartz particles contain a factor that attracts granulocytes.

Presence of a significant number of granulocytes in bronchopulmonary lavage fluid indicates development of a pathological process. This agrees well with the data obtained on exogenic generation of superoxide radicals and hydrogen peroxide during phagocytosis of quartz dust. The fact that rabbit granulocytes stimulated by quartz dust showed enhanced generation of superoxide radicals in only $60 \%$ of all experiments cannot be accounted for adequately so far. In our opinion, this might be related to individual sensitivity of granulocytes of various rabbit species to quartz dust.

The important role of superoxide radicals and hydrogen peroxide in pathogenesis of silicosis is also shown by our data previously obtained on inhibition of the progress of pneumofibrosis in rat lungs in experimental silicosis by exogenic superoxide dismutase and catalase inhaled in the form of aerosol two to five times a week for two and a half months. ${ }^{15-17}$

Requests for reprints to: Dr V A Gusev, Novokosinskaja street 46, korp 2, kv 27, Moscow, 111672 , Russia.

1 De Shazo RD. Current concepts about the pathogenesis of silicosis and asbestosis. F Allergy Clin Immunol 1982;70:41-9.

2 Donaldson K, Bolton RE, Brown CM, Robertson MD, Slight J. Kinetics of bronchoalveolar leucocyte response in rat exposure to equal airborne mass concentrations of quartz, chrysotile asbestos, or titanium dioxide. Thorax 1988;43: 525-33.

3 Haubet A, Rodriguez-Roisin R, Bombi A, Marin AJR, AugstiVidal A. Correlation of bronchoalveolar lavage and functional findings in asbestosis. Am Rev Respir Dis 1986;133 848-54.

4 Myrvik QN, Leake ES, Faris B. Studies on pulmonary alveolar macrophages from the normal rabbit: a technique to procure them in high state of purity. F Immunol 1961;86:128-32.

5 Feldman DL, Mogelsky TC. Use of histopaque for isolation of mononuclear cells from rabbit blood. F Immunol Methods 1987;102:243-9.

6 Hartiala KT, Langlois L., Goldstein IM, Rosenbaum JT. Endotoxin-induced selective dysfunction of rabbit PMN in response to endogenous chemotactic factors. Infect Immun 1985;50:527-33.

7 Lindena J, Burkhardt H. Separation and chemiluminescence properties of human, canine and rat polymorphonuclear cells. F Immunol Methods 1988;115:141-7.

8 Boyum A. Isolation of mononuclear cells and granulocytes from human blood. Scand $\mathcal{F}$ Clin Lab Invest 1968;21 (suppl 97):77-89.

9 Baehner RL, Nathan DG. Quantitative nitroblue tetrazolium test in chronic granulomatous disease. New Engl f Med 1963;278:971-6.

10 Babior BM, Kipnes RS, Curnutte JT. Biological defense mechanism: the production by leukocytes of superoxide: a potential bactericidal agent. $\mathcal{F}$ Clin Invest 1973;52:741-4.

11 Pick F, Keisari J. A simple colorimetric method for the measurement of hydrogen peroxide product by cells in culture. $\mathcal{F}$ Immunol Methods 1980;38:161-70.

12 Schopf RE, Mattar J, Meynburg W, Scheiner O, Hammann KP, Leemel EM. Measurement of the respiratory burst in human monocytes and polymorphonuclear leucocytes by nitroblue tetrazolium reduction and chemiluminescence. $\mathcal{F}$ Immunol Methods 1984;67:109-17.

13 Salin ML, McCord JM. Free radicals and inflammation protection of phagocytosing leucocytes by superoxide dismutase. $\mathcal{F}$ Clin Invest 1975;56:1319-23.

14 Thommasen HV. The role of the polymorphonuclear leucocyte in the pathogenesis of the adult respiratory distress syndrome. Clin Invest Med 1985;8:185-94.

15 Archipova OG, Yaglov VV, Gusev VA, Danilovskaya EV. Effect of superoxide dismutase and catalase on development of fibrose process in lung of rats during experimental silicosis. In: Bioantioxidants. Vol 2. Cheznogolovka: Nanka, 1986; 195. (In Russian.)

16 Gusev VA, Danilovskaja YeV. Role of active oxygen species in pathogenesis of pneumoconiosis. Vopr Med Khim 1987;33: 9-15. (In Russian.)

17 Gusev VA, Danilovskaja YeV, Vatolkina OYe. Effect of mineral dust on generation of superoxide radicals and hydrogen peroxide by alveolar macrophages, granulocytes, and monocytes. Byulletin Eksperimentalnoj Biologii i Meditsiny 1990; 110:372-5.

Accepted 26 October 1992 